\title{
Effects of 8-months yoga training on shaping the spine in people over 55
}

\author{
Małgorzata Grabara
}

Department of Recreation, The Jerzy Kukuczka Academy of Physical Education in Katowice, Poland

\section{Summary}

Study aim: The aim of this study was to evaluate the influence of hatha yoga practices on the shaping of the anteroposterior (AP) spinal curvatures in students of the University of the Third Age, who participated in hatha yoga classes.

Material and methods: 20 women and 5 men took part in the study. Hatha yoga classes were held once a week for 90 minutes over a period of 8 months along with additional exercises including basic positions of hatha yoga in home conditions 1-2 times a week for about 30 minutes. The inclination of the AP curvatures of the spine was measured twice, before and after the end of the classes. A Rippstein plurimeter was used for the measurements.

Results: Measurements of the angle of thoracic kyphosis before starting the series of hatha yoga classes and after finishing them showed a decrease in thoracic curvature in female $(p<0.01)$. In case of the angle of lumbar lordosis, a reduction in this curvature as a result of yoga techniques has been observed in women $(p<0.01)$ too. Amounts of AP curvatures of the spine, measured after completing the series of hatha yoga classes, fluctuated around correct values better than before taking them up.

Conclusion: This study has shown that yoga training leads to an improvement in the habitual body posture in case of aggravating (excessive) AP curvatures of the spine.

Key words: body posture, anteroposterior spinal curvatures, hatha yoga, Rippstein plurimeter

\section{Introduction}

Body posture is characterised by enormous changeability and depends on many different factors, such as e.g. age, sex, general health, type of occupation, physical activity, circadian rhythm. Body posture is related to the physical and mental state of an individual, and it is conditioned by one's efficiency of the kinetic sense, muscular balance and muscle-nerve coordination $[1,8]$. The quality of body posture is determined by the shaping of anteroposterior (AP) curvatures of the spine.

Body posture is a motor habit, characteristic for a given person. Incorrect habit of posture and excessive overload of the spine lead to diseases and pain complaints. Body posture changes during the course of ontogenesis and is subject to deterioration in later period of life. It is related to the ageing process of one's body, which is a result of decreasing one's physical fitness, which is visible in reducing one's muscle strength, reducing the bone mass, worse nerve-muscle coordination, suppleness and balance, or involutional changes in the ligamentous-joints apparatus $[1,26]$. In the sagittal plane, posture deterioration will signify increased thoracic kyphosis and bending the trunk forwards.

Regular physical activity is very important for health; however, in case of elderly people, not every form of physical exercise may be appropriate [17]. The main purpose of physical exercise for the elderly should be keeping fit, lowering the risk of disability and improving the quality of life $[16,23]$. In a programme of exercises for elderly people, emphasis ought to be put on increasing flexibility and strengthening muscles $[6,13]$. One form of physical exercise particularly recommended in this age group might be hatha yoga $[2,17]$. In yoga techniques one adopts a particular body position (asana) slowly, maintains it and relaxes oneself, and then slowly leaves this position. In each asana, one aims at optimal arrangement of the body, elongating the spine by means of active muscle work and correcting one's posture, among other things, due to receptors of deep feeling. The person who practices yoga acquires the skill of maintaining the correct posture, but also expands the range of motion in the joints, improves resistance and muscle strength $[3,9]$. Some authors also point hatha yoga as one of the methods of kinesitherapy [21]. Practicing asanas improves the 
functioning of the whole body, facilitating the work of its individual systems and organs [14, 17, 18, 22, 25]. Thanks to regular hatha yoga practices, the alleviation of pains of the spine may take place [20,27], which is also of considerable significance for the posture.

There are not many studies on the effects of hatha yoga training focusing posture. Few studies have reported the beneficial effects of hatha yoga on postures. Due to the growing interest in this kind of physical recreation, also among elderly, it is justified to investigate whether there is a correlation between systematic yoga practices and posture.

The objective of this study was to assess the effect of hatha yoga training on shaping the anteroposterior curvatures of the spine in the students of the University of the Third Age who attended hatha yoga classes of 90 minutes a week during the period of 8 months. The following research query has been posed: do yoga practices improve the habit of posture, affecting the correct shaping of physiological curvatures of the spine?

A hypothesis, saying that under the effect of hatha yoga practices, the angles of inclination of AP spinal curvatures decrease, has been put forward.

\section{Material and methods}

\section{Subjects}

The study involved 20 women $($ age $=63.3 \pm 6.2$ $\min =55, \max =78$ years old, body height $=159.3 \pm 5.44$, body mass $=68.65 \pm 11.11$, BMI $=26.98 \pm 3.78)$ and 5 men $($ age $=65.5 \pm 6.08 \min =60, \max =75$ years old, body height $=172.4 \pm 2.51$, body mass $=77.78 \pm 5.49$, BMI $=26.19 \pm 2.08$ ), students of the University of the Third Age. Due to a wide age range of the female subjects, they were divided into two groups: 55-60 years old and over 60. People attending the classes had no contraindications to physical exercise, there were no cases of structural postural defects. None of the subjects worked professionally.

This study was approved by the Bioethics Committee of the Jerzy Kukuczka Academy of Physical Education in Katowice, Poland. All the examined persons were informed of the procedures and voluntarily signed consent prior to the measurements.

\section{Exercise prescription}

The subjects were scheduled for one 90-minute session of yoga classes by the Iyengar method per week. The sessions began with the mountain pose (tadasana), a position which forms the habit of correct posture and then poses focusing on lengthening the spine, strengthening muscles, balance, stretching, and finished with relaxation. The subjects attended only yoga classes, therefore one may exclude an influence of other forms of physical activities on the shaping of the spine. In addition, they received a set of home exercises including basic positions of hatha yoga, which they did for 30 minutes 1-2 times a week during the period of this experiment ( 8 months).

The subjects who didn't attend the classes regularly (more than 3 absences), subjects who took up an additional form of physical recreation during the experiment and subjects who couldn't continue to participate in the classes for medical reasons were excluded from the study.

\section{Procedures}

In order to assess the shaping of AP curvatures of the spine, a Rippstein plurimeter (Plurimeter-V; Switzerland) was used. It is a kind of inclinometer filled with oily liquid, including a weight needle, which is always in the vertical line regardless of the position of the device. In addition to the measurements of inclination of AP curvatures, it is also possible to measure mobility with the device.

The subject took up the habitual posture. Measurement of the angle of thoracic kyphosis (ATh) was taken by putting the zeroed device on the $\mathrm{C}_{7}$ process and the upper part of the thoracic section, and then by outlining the kyphosis curve and reading out the result while the device was put above the apex of lumbar lordosis. While measuring the angle of lumbar lordosis (AL), the device was zeroed while placing it on the lumbar-sacral tract and the sacrum, and then the lordosis curve was outlined and its angle was read out with the device placed above the apex of lumbar lordosis. $30^{\circ} \pm 5^{\circ}$ were assumed as correct values for both angles $[7,28]$.

Measurements were carried out before starting the first yoga classes (measurement I) and after finishing the 8-month series of classes (measurement II). It was performed by one person, who measured twice, and in case of a substantial discrepancy (over $5^{\circ}$ ), the angle of kyphosis and lordosis was measured three times. In the first case, the second measurement was taken for analysis, whereas in the second case, extreme measurements were rejected, assuming measurements of intermediate value or repeated ones to be appropriate.

\section{Statistical analysis}

For statistical analysis was used STATISTICA (data analysis software system) version 10. (StatSoft, Inc. 2011) with the use of which they calculated the means, standard deviations (mean $\pm \mathrm{s}$ ) and carried out the statistical analysis of the results of measurement of the angle of thoracic kyphosis and lumbar lordosis, obtained in the first and second measurement by means of the nonparametric test Wilcoxon for dependent samples, achieving the significance level of $p<0.05$. 


\section{Results}

Measurements of the angle of thoracic kyphosis before taking up a series of hatha yoga classes and after finishing them indicate a decrease in the thoracic curvature in women $(p<0.01)$ and in the mixed group (women and men altogether) $(p<0.01)($ table 1$)$.

In case of the angle of lumbar lordosis, the decrease in this curvature as a result of hatha yoga practice was noted in women $(p<0.01)$ and in the mixed group $(p<0.01)$ (table 2). Degrees of anteroposterior curvatures of the spine, measured after completing the series of classes (measurement II), fluctuated closer to correct values than before starting them (measurement I), except for the angle of lumbar lordosis noted in men.

Analysis of the obtained from the first measurement amount of AP curvatures with regard to their right values $\left(30^{\circ} \pm 5^{\circ}\right)$ showed that as much as $92 \%$ of the subjects, both men and women, had increased thoracic kyphosis, while $8 \%$ of the subjects had the right kyphosis angle. Only 35\% women had increased lumbar lordosis, and $11 \%$ of the subjects could boast the right value of that curvature. However, in measurement II, the right values were obtained by more people than in measurement $\mathrm{I}$, since the angle of kyphosis was correct in $24 \%$, and of lordosis in $52 \%$ of all the subjects (fig. 1).

\section{Discussion}

The posture of elderly people is subject to unfavorable changes which, among other things, result in moving the center of gravity forwards, bending the trunk, an increase in thoracic kyphosis and flattening of lumbar lordosis. Results of the study of people over 75 years showed a significant advantage kyphotic type in both men and women [1]. Measurements of the thoracic kyphosis angle taken during the first measurement have proved that it is considerably increased in people over 55 years of age (92\%), both men and women. Similar results were obtained by other researchers $[1,15]$. In a study by Ostrowska et al. a distinct predominance of the kyphotic posture has been noticed along with a greater value of the thoracic kyphosis angle, as well as a reduced angle of lumbar lordosis in older, physically active men in comparison with young men - students of the Academy of Physical Education [19]. Observed abnormalities in the posture within the sagittal plane in the elderly are quite common. It results from other studies that this condition does not have to be the result of osteoporosis [11]. Increased thoracic kyphosis or else lumbar lordosis may lead to the occurrence of considerable pain complaints as a result of excessive pressure on muscles and neck ligaments. Coexistence of increased lumbar lordosis then leads to strains of vertebral joints of the lower spine. Increased thoracic

Table 1. Mean \pm s values of the angle of thoracic kyphosis (ATh) before taking up hatha yoga classes (measurement I) and after finishing them (measurement II) in the students of the University of the Third Age

\begin{tabular}{lccccc}
\hline & $\begin{array}{c}\text { measurement I ATh }\left[^{\circ}\right] \\
\pm \mathrm{s}\end{array}$ & $\begin{array}{c}\text { measurement II ATh }\left[^{\circ}\right] \\
\pm \mathrm{s}\end{array}$ & $\mathrm{N}$ valid & $\mathrm{Z}$ & $p$ \\
\hline Men $(\mathrm{n}=5)$ & $49.2 \pm 13.76$ & $46 \pm 12.94$ & 4 & 1.83 & 0.07 \\
Women aged 55-60 $(\mathrm{n}=8)$ & $41.00 \pm 4.57$ & $37.75 \pm 4.3$ & 8 & 2.52 & 0.01 \\
Women aged over 60 $(\mathrm{n}=12)$ & $42.42 \pm 5.68$ & $39.5 \pm 5.27$ & 8 & 2.52 & 0.01 \\
Women together $(\mathrm{n}=20)$ & $41.85 \pm 5.18$ & $38.8 \pm 4.86$ & 16 & 3.75 & $<0.01$ \\
Altogether $(\mathrm{n}=25)$ & $43.32 \pm 7.86$ & $40.24 \pm 7.43$ & 20 & 3.92 & $<0.01$ \\
\hline
\end{tabular}

Table 2. Mean $\pm s$ values of the angle of lumbar lordosis (AL) before taking up hatha yoga classes (measurement I) and after finishing them (measurement II) in the students of the University of the Third Age

\begin{tabular}{|c|c|c|c|c|c|}
\hline & $\begin{array}{c}\text { measurement I AL }\left[^{\circ}\right] \\
\pm \mathrm{s}\end{array}$ & $\begin{array}{c}\text { measurement II AL }\left[^{\circ}\right] \\
\pm s\end{array}$ & $\mathrm{~N}$ valid & $\mathrm{Z}$ & $p$ \\
\hline $\operatorname{Men}(n=5)$ & $22.2 \pm 9.44$ & $21.2 \pm 6.57$ & 3 & 1.5 & 0.42 \\
\hline Women aged 55-60 $(n=8)$ & $36.38 \pm 10.88$ & $34 \pm 9.37$ & 6 & 2.20 & 0.03 \\
\hline Women aged over $60(n=12)$ & $29.58 \pm 7.12$ & $27.25 \pm 5.38$ & 7 & 2.37 & 0.02 \\
\hline Women together $(n=20)$ & $32.3 \pm 9.19$ & $29.95 \pm 7.78$ & 13 & 3.18 & $<0.01$ \\
\hline Altogether $(n=25)$ & $30.28 \pm 9.94$ & $28.2 \pm 8.24$ & 16 & 3.02 & $<0.01$ \\
\hline
\end{tabular}




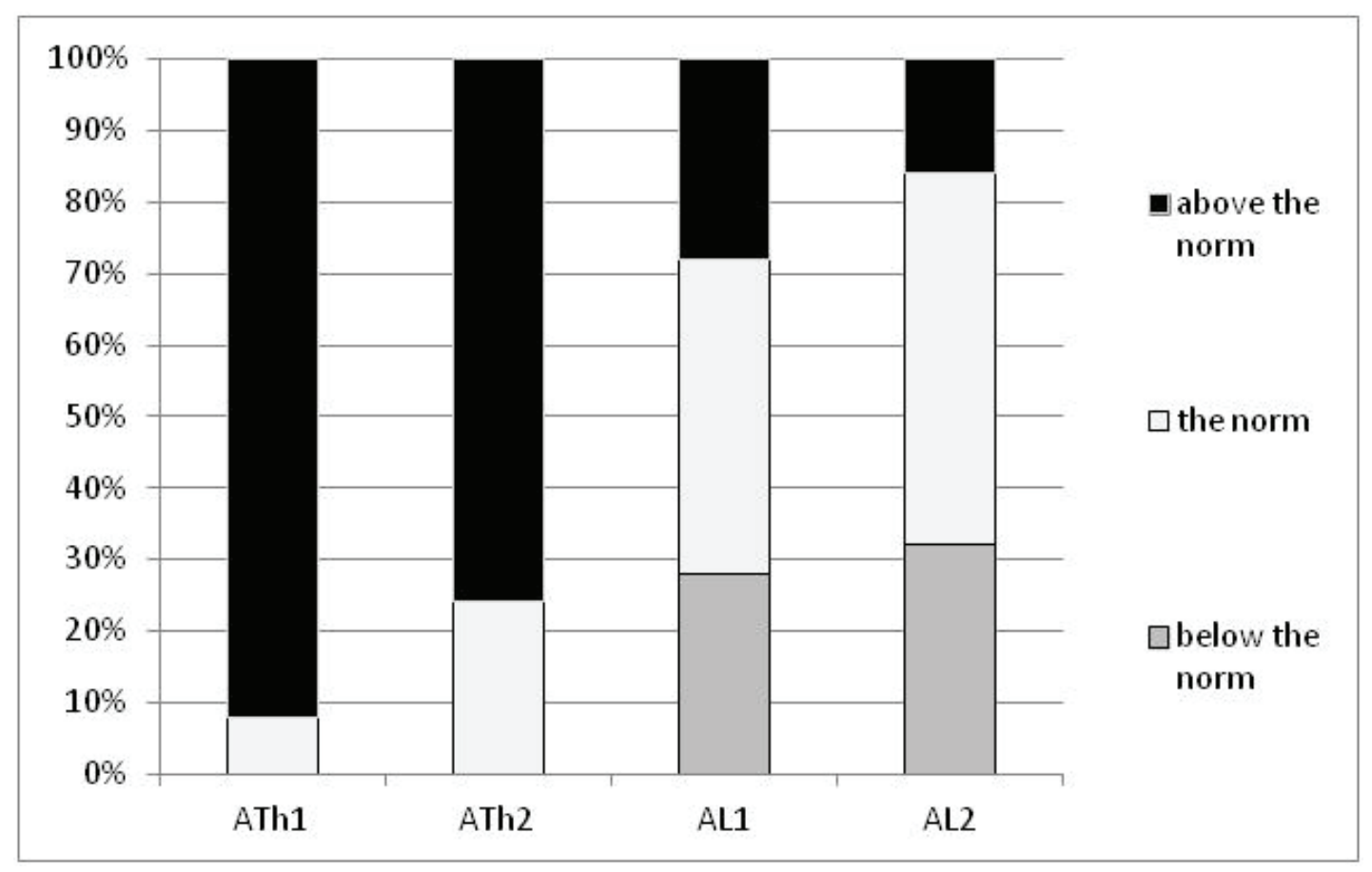

Fig 1. Presence of correct and increased or flattened thoracic kyphosis (KTH) and lumbar lordosis (KL) among men and women $(n=25)$ in the first and second measurements in the light of normal value $\left(30^{\circ} \pm 5^{\circ}\right)$

kyphosis may also reduce the range of motion of the cervical and thoracic regions [5]. Thoracic hyperkyphosis might also cause respiratory system disorders [4], but also expose the subject to the risk of more frequent clinical fractures [12].

Presented study revealed that a significant decrease of the angle of thoracic kyphosis and lumbar lordosis occurred in women over 55 years of age, under the influence of hatha yoga. In men, there were not statistically significant differences between first and second measurement.

Most hatha yoga asanas are performed on the elongated spine. This takes place due to active work of postural muscles and results in a reduction in the pelvic anteversion, relaxation of the muscles of the lumbar section and flattening of lumbar lordosis. Such exercises contribute to the formation of the habit of active posture, with an elongated spine, protruding chest, pulled in the abdomen and gently outlined (not deepened) AP curvatures of the spine. Thus, hatha yoga practices are especially beneficial for people with deepened spinal curvatures while in case of a reduction in their angles (or an angle of one of the curvatures), one should modify positions and choose those which shape lumbar lordosis or/and thoracic kyphosis, so that they no longer contribute to the flattening of one or both physiological curvatures of the spine.

Findings of the current study receive confirmation in the study by Greendale et al., carried out among 118 women and men over 60 years of age. It has been proved that there was a statistically significant decrease in the excessive kyphosis angle (amounting to over 40 degrees) in people attending hatha yoga classes for 24 weeks, 3 times a week, in comparison to people not participating in exercises [10]. The effect of improved posture as a result of hatha yoga practices is also confirmed by the examination of 10-year-old children's posture [24] and an assessment of the shaping of anteroposterior curvatures of the spine in university students [7]. On the other hand, analysis of the posture of people who practiced hatha yoga for a longer period of time has shown that the configuration of body elements in the mountain position, which is a basic body alignment in the yoga asanas, is better than in the habitual stance [8].

Due to the increasing popularity of hatha yoga, further research into the influence of yoga practices those who exercise in various aspects of health and fitness, seems appropriate. Particularly substantial meaning may be assigned to studies among elderly people since yoga is one of few forms of physical recreation, which may be recommended, regardless of age or physical fitness level.

\section{Conclusions}

Hatha yoga practices lead to the decrease in excessive AP curvatures of the spine in people who are over 
55 years of age, which usually results in an improvement in the habitual posture. They are particularly beneficial for people with excessively deepened thoracic kyphosis.

\section{References}

1. Anwajler J., K.Barczyk, D.Wojna, B.Ostrowska, T.Skolimowski (2010) Characteristics of body posture in the sagittal plane in elderly people - residents of social care centres. (In polish. engl. Abstract). Gerontol. Pol., 8(3): 134-139.

2. Chen K.M., W.S.Tseng, L.F.Ting, G.F.Huang (2007) Development and evaluation of a yoga exercise programme for older adults. J. Adv. Nurs., 57(4): 432-441. DOI: 10.1111/j.1365-2648.2006.04115.

3. Chen K.M., W.S.Tseng (2008) Pilot-Testing the Effects of a Newly-Developed Silver Yoga Exercise Program for Female Seniors. J. Nurs. Res., 16(1): 37-45.

4. DiBari M., M.Chiarlone, D.Matteuzzi, S.Zacchei, C.Pozzi, V.Bellia, F.Tarantini, R.Pini, G.Masotti, N.Marchionni (2004) Thoracic kyphosis and ventilatory dysfunction in unselected older persons: An epidemiological study in Dicomano, Italy. J. Am. Geriatr. Soc., 52: 909-915.

5. Ettinger B., D.M.Black, M.Palermo, M.C.Nevitt, S.Melnikoff S.R.Cummings (1994) Kyphosis in older women and its relation to back pain, disability and osteopenia. The study of osteoporotic fractures. Osteoporos. Int., 4: $55-60$.

6. Gauchard G.C., C.Jeandel, A.Tessier, P.P.Perrin (1999) Beneficial effect of proprioceptive physical activities on balance control in elderly human subjects. Neuroscience Letters, 273(2): 81-84.

7. Grabara M., J.Szopa (2011) Effects of hatha yoga on the shaping of the antero-posterior curvature of the spine. Hum. Mov., 12(3): 259-263.

8. Grabara M., J.Szopa (2011) Habitual body posture and mountain position of people practicing yoga. Biol. Sport, 28: 51-54.

9. Grabara M., J.Szopa, D.Grabara (2011) Flexibility of the spine and selected joint in women practising hatha yoga. Pol. J. Sport. Med., 27(1): 61-73.

10. Greendale G.A. M.H.Huang, A.S.Karlamangla, L.Seeger, S.Crawford (2009) Yoga Decreases Kyphosis in Senior Women and Men with Adult-Onset Hyperkyphosis: Results of a Randomized Controlled Trial. J. Am. Geriatr. Soc., 57: 1569-1579.

11. Grey C., R.Young, P.W.Bearcroft, J.E.Compston (1996) Vertebral deformity in thoracic spine in post-menopausal women: value of lumbar spine bone density. Br. J. Radiol. 69: 137-142.

12. Huang M.H., E.Barrett-Connor, G.A.Greendale, D.M.Kado (2006) Hyperkyphotic Posture and Risk of
Future Osteoporotic Fractures: The Rancho Bernardo Study. J. Bone. Miner. Res., 21(3): 419-423. DOI: 10.1359/ JBMR.051201.

13. Jachimowicz V., T.Kostka (2009) Association between physical activity and functional and motor abilities among the elderly. Pol. J. Sport. Med., 25(4): 256-264.

14. Jacobs G.D. (2001) Clinical applications of the relaxation response and mind-body interventions. J. Altern. Complement. Med., 7(Suppl.1): 93-101.

15. Kabsch A. (2001) Disability accompanies aging challenge for physiotherapy. (In Polish) Fizjoterapia 9(3): 3-19.

16. Keysor J.J. (2003) Does late-life physical activity or exercise prevent or minimize disablement? A critical review of the scientific evidence. Am. J. Prevent. Med., 25(3,Suppl 2): 129-136.

17. Kraemer J.M., D.Marquez (2009) Psychosocial correlates and outcomes of yoga or walking among older adults. J. Psychol., 143(4): 390-404.

18. Kumar C.S. (2009) Comparative effect of specific yogic exercises and combination of specific yogic exercises with autogenic training on vital capacity of the middle aged men. J. Phys. Edu. Sport/Citius Altius Fortius, 25(4): 45-47.

19. Ostrowska B., K.Rożek-Mróz, C.Giemza (2003) Body posture in elderly, physical active males. The Aging Male, 6: 222-229.

20. Padmini T., S.Chametcha, N.H.Ramarao, R.Nagarathna (2008) Effect of Short-Term Intensive Yoga Program on Pain, Functional Disability and Spinal Flexibility in Chronic Low Back Pain: A Randomized Control Study. J. Altern. Complement. Med., 14(6): 637-644.

21. Posadzki P., S.Parekh (2009) Yoga and Physiotherapy: A Speculative Review and Conceptual Synthesis. Chin. J. Integr. Med., 15(1): 66-72.

22. Raub J.A. (2002) Psychophysiologic Effects of Hatha Yoga on Musculoskeletal and Cardiopulmonary Function: A Literature Review. J. Altern. Complement. Med., 6: 797-812.

23. Rejeski W.J., L.R.Brawley, S.A.Shumaker (1996) Physical activity and health-related quality of life. Exerc. Sport Scie.Rev. 24: 71-108.

24. Savić K., D.Pfau, S.Skorić, J.Pfau, N.Spasojević (1990) The effect of Hatha yoga on poor posture in children and the psychophysiologic condition in adults. Medicinski Pregled, 43: 268-272.

25. Tran M.D., R.G.Holly, J.Lashbrook, E.A.Amsterdam (2001) Effects of hatha yoga practice on the health-related aspects of physical fitness. Prev. Cardiol., 4: $165-170$.

26. Vale R.G.S., R.D.Oliveira, C.S.Pernambuco, Y.P.S.F.Meneses, J.S.Novaes, A.F.D.Andrade (2009) Effects of muscle strength and aerobic training on basal se- 
rum levels of IGF-1 and cortisol in elderly women. Arch. Gerontol. Geriatr., 49: 343-347.

27. Williams K.A., J.Petronis, D.Smith, D.Goodrich, J.Wu, N.Ravi, E.J.Doyle, J.R.Gregory, K.M.Munoz, R.Gross, L.Steinberg (2005) Effect of Iyengar yoga therapy for chronic low back pain. Pain, 115(1/2): 107-117.

28. Zwierzchowska A., K.Gawlik, J.Dudek, J.Graca, D.Palica (2008) Evaluation of body posture in first years students of the University of Economist in Katowice. Pol. J. Sport. Med., 24: 37-44.

Received 20.06.2013

Accepted 04.11.2013

(C) University of Physical Education, Warsaw, Poland 